\title{
A Comprehensive Study on IoT security problems based on blockchain
}

Name- Chandni*

*Chandigarh university

\begin{abstract}
IoT refers to other enhancements that integrate with the virtual and related and interactive, and create new digital organizations that build our self-sufficiency. IoT provides several performance, not to mention, collaborations now presenting different issues with the same areas of appeal, security, security, integrity and direct data. These issues are preventive in anticipation of what might come of the success of IoT applications. This study gives a general summary of IoT integration with blockchain development. An internal and external measurement of the combination of block-chain to IoT model has been introduced, which has the advantages of access and will how blockchain will solve IoT concerns. Blockchain designing can be utilized as a help for different IoT applications. This is trailed by a glance at the effect of coordinating man-made consciousness (AI) into IoT and blockchain. At long last, the effect of blockchain on IoT investigation is tended to.
\end{abstract}

Keywords: Internet of Things (IoT) framework; blockchain; IoT with block-chain; Artificial Intelligence (AI), WSN.

\section{Introduction}

The IoT is an advanced innovation where different physical and virtual gadgets can be associated and speak with one another absurd frequently without human intercession. IoT devices have become overused to solve our ongoing problems and enrich our lives by testing and gathering more information about our environment that has been used to make the most of our experiences release new management. IoT has become huge worldwide, with millions of eyesight and use worldwide to this day with many customers [1]. Although there are many advantages of the IoT framework in different areas, robust IoT engineering, with the ultimate goal of integrating, monitoring and driving all IoT products by one staff member focal, facing many difficulties. For example, the symbol of frustration, in which, if an employee loses, all IoT applications and administration are subject to its loss, affecting the access and status of Leadership is provided by the IoT framework [2] [3]. In addition, in-house staff sell all the data created by setting up different IoT devices in a single area (focal staff), which makes it an attractive target for some objections [4]. With so many issues unfolding by the IoT developer, moving IoT to one of these applications can be a good decision. Among the traditional and famous types of explosive progress is the blockchain. It is practically data sharing, distribution, sharing and non-exchange, which stores the data of the different exchange that is always present in some distribution (P2P) [5] [6] .

A selection of exchanges was collected and given a place in the record. The blockchain is named for the fact that it creates chains of blocks. Most hubs in the blockchain enterprise can document their knowledge in order to store a transaction in the disseminated record [7]. Using blockchain to connect IoT devices has a number of advantages. In addition, blockchains provide better authentication and protection because they use these cryptography calculations, hash capacities, and timestamps, all of which provide a more stable operating environment. In addition, the blockchain and database logger protects the data against malicious attacks and ultimately the target cannot place any data changes in the database if a large number of users contribute authenticated [8] [9].

This study gives a general overview of the IoT with block-chain. This study discusses new and important aspects of the IoT blockchain, for example, blockchain such as IoT support and the impact of AI integration on IoT and blockchain. The research network ignored blockchain research in IoT applications [10] [11].

\subsection{An outline of the IoT framework}

The term IoT alludes to the advanced expansion of web empowered gadgets with inserted registering capacity. The term depicts a wide scope of innovations, from the web empowered surveillance cameras and reconnaissance gadgets, and arranged mechanical gear and sensors to homegrown items like ice chests and vehicles. The IoT is an always progressively well-known innovation that has created with universal registering in the present period of innovation [12] [13] [14]. 
This number is based on the total development of up to 75 billion gadgets with the end of 2025, as shown in Fig 1 .

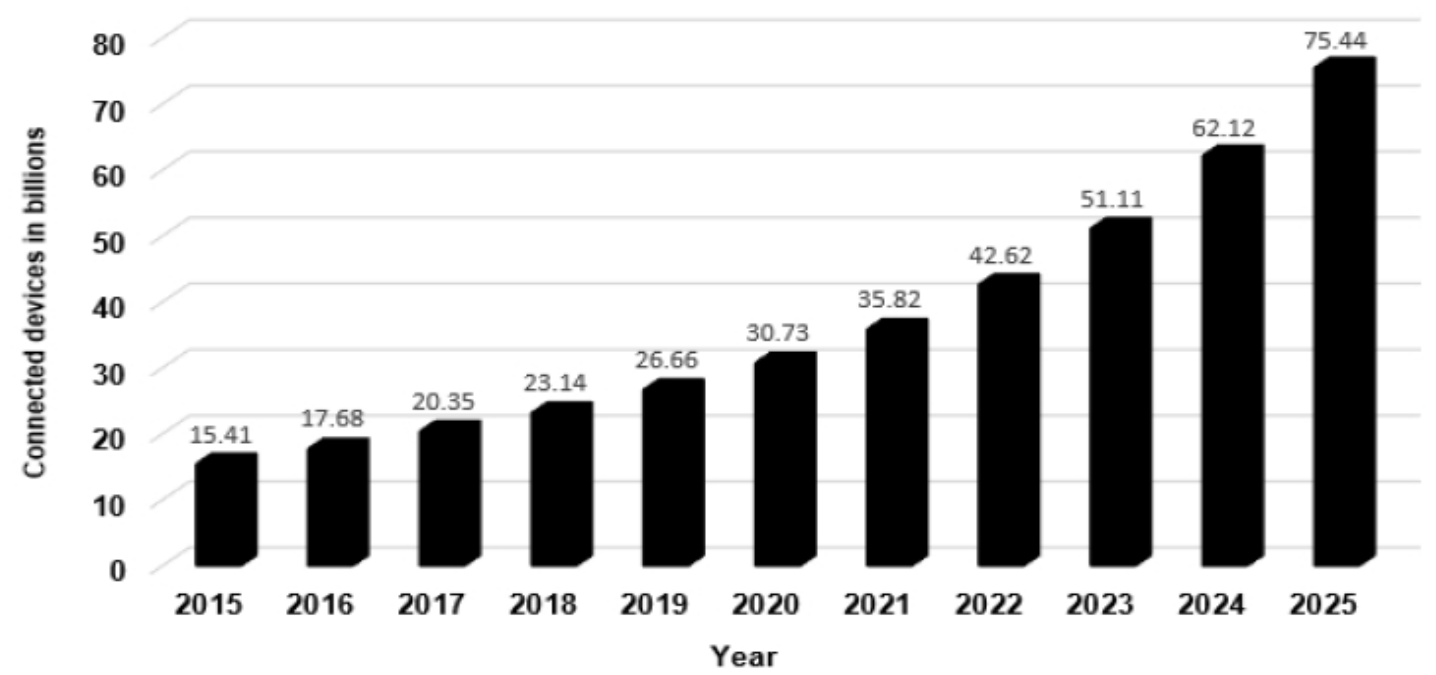

Fig 1. IoT growth chart from 2015 to 2025 [3].

Also, the IoT arcade is developing dramatically. As indicated by statistically, the assessed income of Internet of Things in 2015 was USD 743 billion [15].

\subsection{IoT Framework Features:}

The IoT foundation defines innovative ideas can completely transforms us, our business and our economy. IoT manufacturing end -to -end management and embedded applications offer some advantages than the current standard. These applications and management share significant things, include [16, 17]:

a. Sensing capabilities: WSN is usually a set of sensors that collect data about environmental conditions and send it to a central server for processing. Sensors are the IoT's structure squares, allowing for the collection of both constant and context-based data regarding environmental conditions, allowing chiefs to make precise and timely decisions.

b. Connectivity: the vital qualities of the IoT framework that empowers billions of gadgets and objects to be open distantly. Also, it permits different articles in our current circumstance to be associated and speak with one another ridiculous, which permits making new applications and administrations.

c. Large scale network: This huge number of gadgets and items make an enormous scope network that can't be overseen by conventional or old style techniques.

d. Dynamic system: It can associate different articles in various areas. Moreover, with sensors that gather different continuous and relevant data about environmental factors, IoT gadgets can be progressively adjusted to changing situation and conditions.

e. Intelligence capabilities: with cutting edge equipment, programming and detecting capacities that empower gathering a huge volume of relevant information, IoT gadgets can settle on savvy choices in a few conditions and participate keenly with other working together articles.

f. Big data: here are many of IoT gadgets that makes tremendous bulk of information that can't be dissected utilizing conventional information examination techniques. This alludes to the expression "large information". The IoT is among the most extravagant wellsprings of huge information that makes an immense volume of information that needs inventive investigation strategies to have the full advantages of IoT information.

g. Unique identification: Internet of Things framework empowers different items to interface over the Internet. Being able to associate with the Internet can be ensured just if every gadget have a remarkable character, for example, the IP address. Along these lines, in spite of the fact that IoT gadgets are in billions, every gadget has a remarkable personality. 
h. Independent decision: here is numerous sensors in the IoT framework, which empower gathering colossal context oriented and ongoing information about the general climate. These unique information permit IoT gadgets to settle on setting mindful and self-sufficient choices.

i. Heterogeneity: the IoT framework permits various gadgets and objects to be addressable and speak with one another preposterous. These gadgets accompany heterogeneous qualities including correspondence conventions, working frameworks, stages, and other programming and equipment segments. Notwithstanding these heterogeneous attributes, the IoT framework permits every one of these gadgets to speak with one another proficiently and viably.

\subsection{Centralized IoT Architecture}

Dealing with a bunch of hubs to cooperate to plan a framework needs to have a specific engineering plan. Among the famous plans is the concentrated engineering, which is fabricated utilizing a unified worker to control and deal with a bunch of hubs. These hubs differ from a high level PC framework, PC, cell phone, and so forth, which are fit for performing different sorts of activities. The unified worker goes about as the director that manages all solicitations coming from different hubs and oversees task planning and portion among hubs in the organization [18, 19]. A basic type of a brought together design is appeared in Fig 2, where all hubs in the organization are associated through a focal worker.

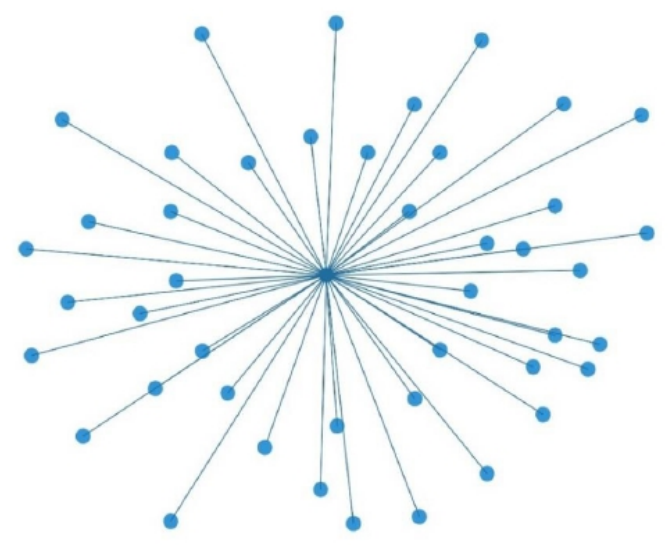

Fig 2. Centralized architecture of IoT.

The concentrated IoT comprises of three key layers; the perception layer, network layer and application layer, as demonstrated in Fig 3.

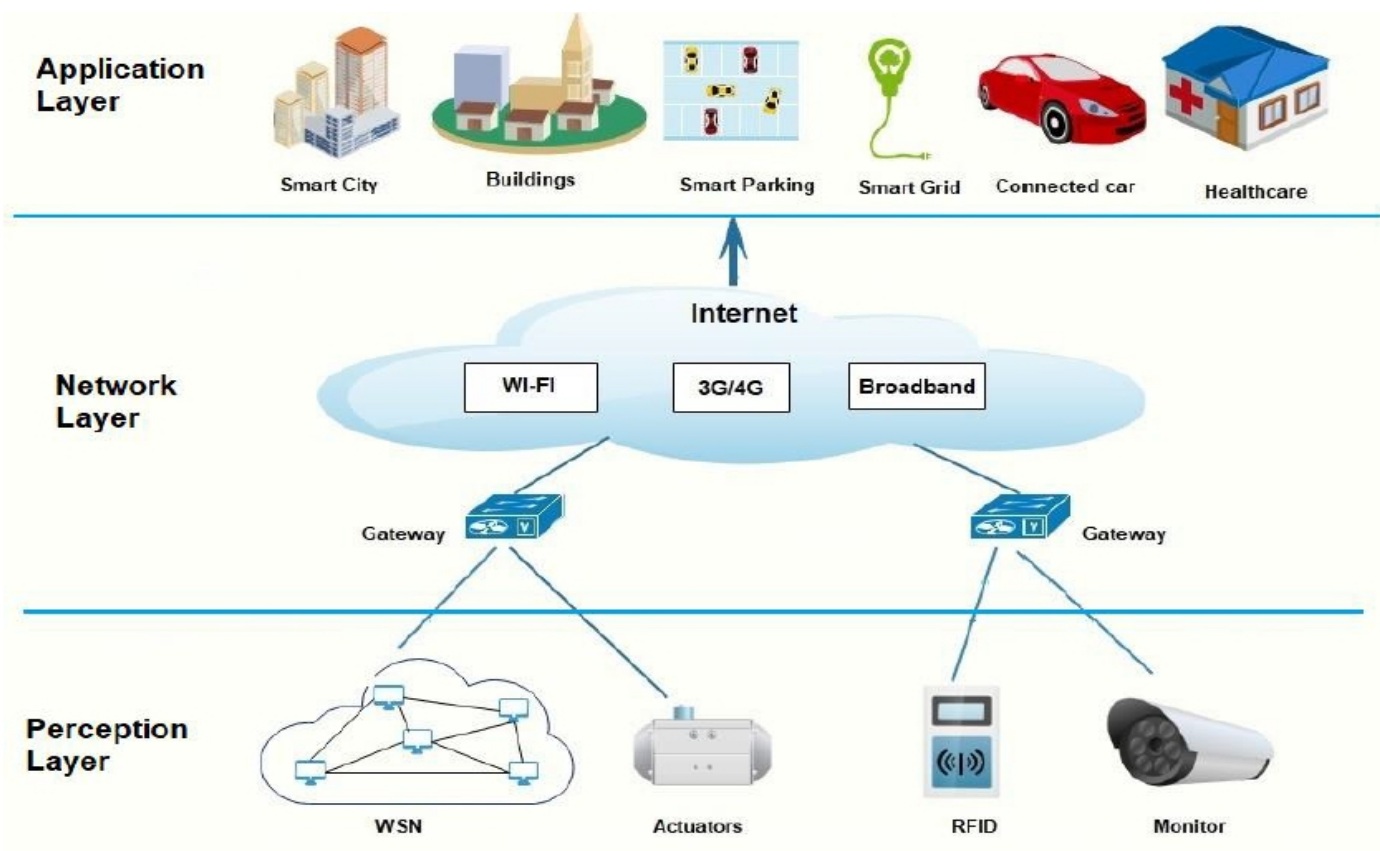


Three layer IoT system architecture

Table 1 shows a synopsis of the difficulties of the reunited IoT model.

Table 1. Synopsis of difficulties of the IoT brought together model.

\begin{tabular}{|c|c|}
\hline Task & Explanation \\
\hline $\begin{array}{c}\text { Failure of Single } \\
\text { Point }\end{array}$ & $\begin{array}{l}\text { Unified worker plays out all handling activities and oversees correspondences between } \\
\text { different gadgets, this delivers a solitary mark of disappointment where if the worker } \\
\text { goes down, entire organization of gadgets will be inaccessible [25]. }\end{array}$ \\
\hline Security & $\begin{array}{l}\text { Security is amongst the vital difficulties in IoT brought together prototypical since } \\
\text { information handling activities or information stockpiling are complete in one area } \\
\text { [26]. }\end{array}$ \\
\hline Privacy & $\begin{array}{l}\text { Different kinds of continuous information including delicate data are gathered from } \\
\text { IoT gadgets like propensities, passwords, individual and monetary data, and so on } \\
\text { [27]. }\end{array}$ \\
\hline Inflexibility & $\begin{array}{l}\text { To deal with this responsibility, the unified worker designs the heap to sidestep top } \\
\text { burden issues. Be that as it may, this cutoff points client adaptability while finishing } \\
\text { their own undertakings because of the tight plan and postpone connected to this cycle } \\
{[28] \text {. }}\end{array}$ \\
\hline Cost & $\begin{array}{l}\text { The focal worker plays out all preparing and correspondence activities between all } \\
\text { hubs in the organization which require high equipment and programming capacities to } \\
\text { deal with this responsibility. Furthermore, it needs enormous holding stockpiles that } \\
\text { can store information coming from different IoT gadgets. Every one of these high } \\
\text { abilities of equipment and programming accompany a significant expense [29]. }\end{array}$ \\
\hline Scalability & $\begin{array}{l}\text { Utilizing the idea of an incorporated framework with enormous undertaking } \\
\text { associations that include a few branches in various zones will be outlandish. The } \\
\text { quantity of IoT gadgets is expanding continually which implies that the brought } \\
\text { together model can't scale and capacity proficiently [30]. }\end{array}$ \\
\hline Access and Diversity & $\begin{array}{l}\text { Among the significant parts of a proficient framework is the ability to furnish } \\
\text { admittance to every one of their clients with assorted necessities. Nonetheless, the } \\
\text { concentrated framework requires its clients to get to the data consistently utilizing } \\
\text { indistinguishable cycles. Moreover, most brought together frameworks use a specific } \\
\text { working framework for the entire organization which confines variety inside the } \\
\text { organization [31]. }\end{array}$ \\
\hline
\end{tabular}

\section{Section 3:}

\subsection{An outline of blockchain innovation}

The world continued to use the built-in design, a central worker is expected to control the preparation and reservation of tasks until Szabo achieved advanced decentralized cash in the late 1990s. Ten years later, the digital currency Bitcoin was offered [32]. This part presents an outline of blockchain innovation.

\subsection{An Overview of Blockchain}

Innovation is one of the latest topics to draw the attention of several associations and analysts because of the many advantages it has given over existing arrangements [33]. A blockchain is practically a transmitted, decentralized and unchanged record, which stores the data of the various exchanges that have taken place constantly in a given P2P network [34] [35]. On this line, many blocks are linked together and are called blockchains. The hash work is mainly used to approve the trust of the substance or information of the block [36] [37] [38].

\subsection{Blockchain Components}

Blockchain innovation can offer several advantages over the current system. There are lots of original parts of a blockchain, which include a record, a block, a hash, a division, a minor, and an agreement, as described in Figure 4. The file is an information type used to store different types of data [39]. There are many differences between a traditional database and a registry. A data set framework stores information as tables with segments and columns. In addition, it utilizes a social model for questioning and assembling information by associating data from a few sources [40]. Then again, the record is used to store every one of the exchanges that were at any point produced 
using all taking part clients in the organization. Moreover, the record was conveyed among the partaking hubs, so every client has its own imitation of the record.

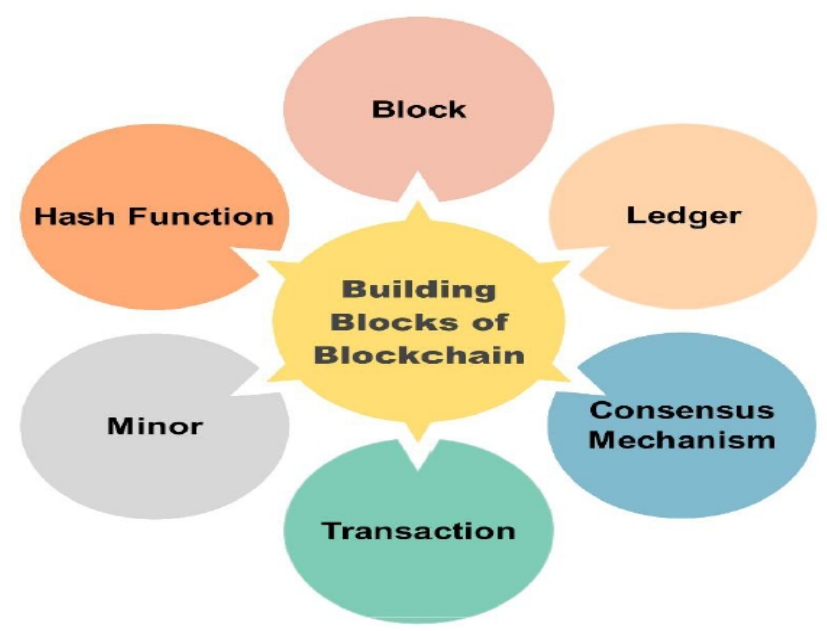

Fig 4. Blockchain's Main components

The hash function is used to identify the subject information of each block. In fact, the hash function is a numeric function that small children need to fold to obtain a block. The motivation to use the hash function is such that it has no effect making it difficult to create two flags that cannot be used for two different data types [41]. A variation of the littlest unit of cycles or movements in which trades are combined and separated into a block [42].

\subsection{Blockchain Features}

Blockchain can convey various aids for numerous fields and applications. This novel innovation shares some normal highlights that include:

a. Decentralization: block-chain is ordinarily a decentralized and conveyed climate that depends on the P2P correspondence between imparting hubs.

b. Transparency: rather than the unified model where the focal worker is just having the full control and admittance to all information, blockchain offers a decent degree of straightforwardness wherein all hubs approach every one of the subtleties of the exchanges that always occurred in their organization. Also, every hub has a duplicate of the circulated record to keep refreshed with changes. Also, the shortfall of an outsider builds business agreeableness and trust [43].

c. Immutability: among the urgent attributes of blockchain is the ability of ensuring the exchanges' trustworthiness through delivering unchanging records. As opposed to the incorporated model where information respectability is just overseen and safeguarded through the focal position [44].

d. Better security: among the benefits of block-chain innovation is that it gives better security over existing arrangements [41].

e. Anonymity: in spite of blockchain using a record that is disseminated between all clients, blockchain gives an unknown personality to secure the hubs' protection [43].

f. Cost reduction: as opposed to the concentrated design in which the high level and complete equipment and programming framework is needed to fabricate the incorporated worker, the blockchain innovation lessens the costs identified with fitting and supporting enormous unified workers as it uses the preparing force of imparting gadgets [45].

g. Autonomy: the capacity to settle on self-sufficient choices is among the highlights that the blockchain innovation can give. It permits the assembling of new gadgets that can settle on savvy and self-governing choices [46].

Section 4:

4.1 Reconciliation of IoT with block-chain 
The IoT has gotten one of the exceptional innovations that empower virtual and actual items to be connected together ludicrous, which thus produce various freedoms in various areas. The sudden advancement of the IoT framework has opened imaginative possibilities in different fields. The current IoT concentrated model uses an outsider focal power that has unlimited oversight of information assortment and preparing from different IoT objects with no reasonable limitations about how the gathered information are being utilized [47]. Then again, blockchain innovation conveys decentralized, self-governing, trustless and circulated climate [48].

Table 2. A comparison between blockchain and IoT.

\begin{tabular}{|c|l|l|}
\hline Objects & \multicolumn{1}{|c|}{ Internet of Things } & \multicolumn{1}{c|}{ Block-chain } \\
\hline Privacy & Less private & Higher privately for nodes \\
\hline Band-width & $\begin{array}{l}\text { Internet of Things gadgets restricted data } \\
\text { transfer capacity and assets. }\end{array}$ & High consumption of bandwidth \\
\hline System Structure & Centralized & Decentralized \\
\hline Scalability & large number of devices & Not supported large network \\
\hline Resource & Limited Resource & Consuming Resource \\
\hline Latency & Need less latency & Time-consuming Block mining \\
\hline Security & Security issues & Higher security \\
\hline
\end{tabular}

\subsection{IoT with Block-chain Architecture}

Incorporating block-chain with IoT has been a must in order to overcome the challenges of a single IoT architecture and take advantage of the limitless benefits of blockchain progress. Using blockchain in conjunction with IoT can be done in a variety of ways. This section features a discussion of one of the methodologies for combining blockchain and IoT in a layered architecture. There are four layers in the simple layered blockchain with IoT architecture. [53].

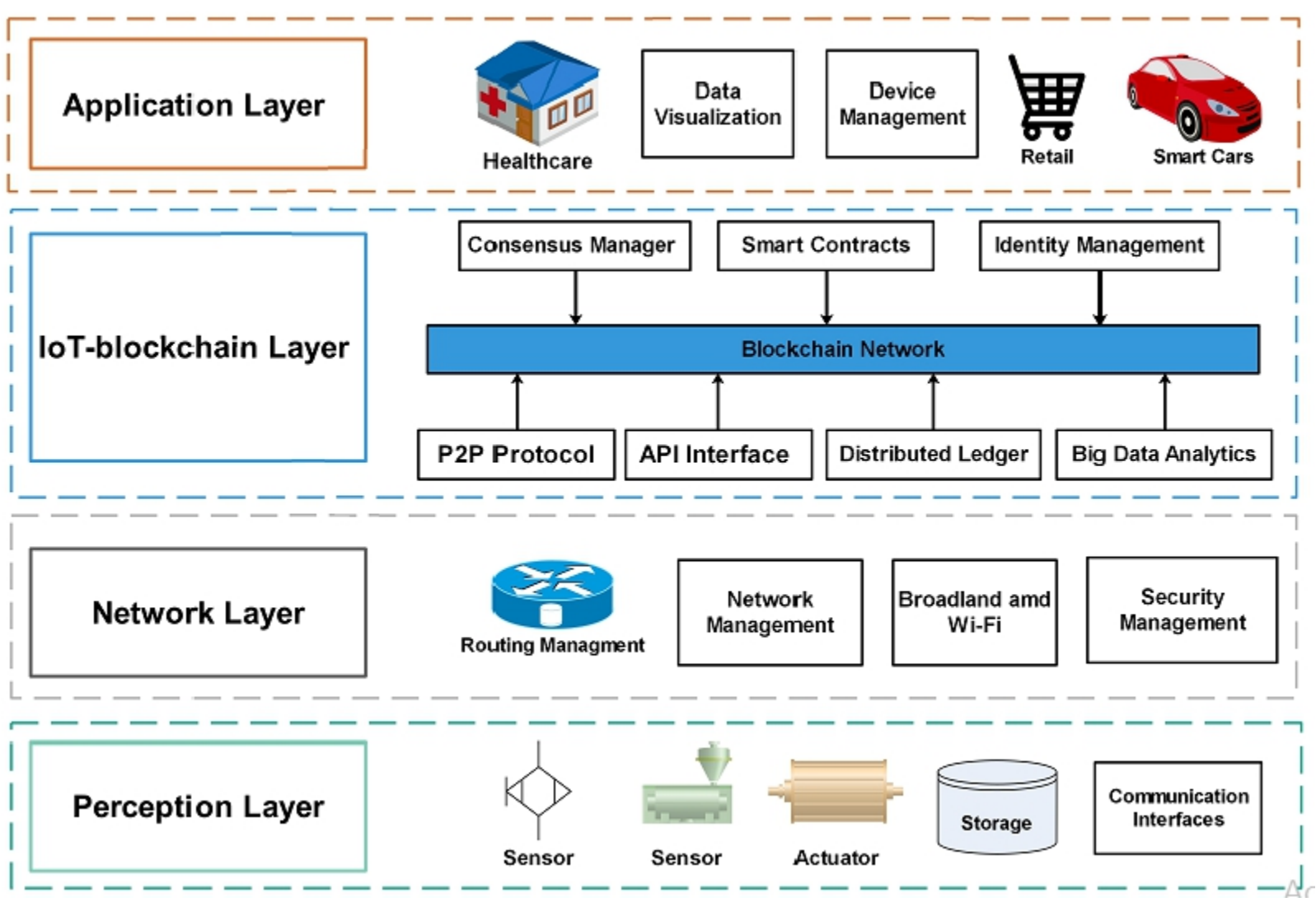

Fig 5. IoT with blockchain Architecture. 


\subsection{Blockchain with IoT Implementation}

The first item used for financial transfers and computerized cash was blockchain, which allows all central points in the block-chain network to conduct and manage transactions. By then, the block-chain is made up of various rooms, hence the enormous advantages it provides. The Internet of Things is one of these territories. Combining blockchain technology with the Internet of Things will offer limitless advantages to a variety of IoT applications. [54] [55].

\subsection{IoT with Blockchain Recent Studies}

Coordinating blockchain innovation with IoT is one of the most pressing challenges that has drawn the attention of a variety of experts to help solve the challenges of concentrated IoT tech. Some exams, for example, have adopted blockchain as a conclusive solution to the IoT framework's security and privacy problems. Khan and Salah [64], for example, discussed an IoT audit and the security problems associated with layered IoT models. The developers then separated the IoT framework's security requirements from cutting-edge arrangements. The paper also presented blockchain technology as a critical tool for determining the majority of the IoT system's security problems. In addition, Polyzos and Fotiou [41] discuss the blockchain's engineering capability and examine the IoT framework's protection requirements and how coordinating the IoT with the blockchain will address these security issues. Its foundation allowed for continuous verification and control between the end user and the device. The use of blockchain technology was proposed as a way to provide a more effective and powerful access management system. The development network has also embraced blockchain. Rejeb et al. [71] did research on the arrangement of blockchain innovation with IoT and the expected advantages of this combination in the inventory network space. Likewise, they talked about the effect of blockchain on the main highlights of the IoT structure. Some experts have provided efficient written research to help the user obtain accurate information on certain exploitation issues. For example, Conoscenti et al. [60] conducted an efficient newsroom audit to collect data and information about the current jobs in blockchain innovation to approve its ability to provide better security, obscurity and flexibility over existing advances. They have ranked the new blockchain workers. Similarly, Abadi et al. [74] performed a thorough handwriting audit in blockchain-IoT coordination. Various experts conducted audits and provided overviews in order to investigate the intersection of blockchain and IoT. The dedication of the late exams that examined the blockchain's reconciliation with the IoT is summarized in Table 5 .

Table 5. A summary of recent research on blockchain integration with IoT.

\begin{tabular}{|c|l|}
\hline Citation & \multicolumn{1}{|c|}{ Contribution Summary } \\
\hline Salah and Khan [16] & $\begin{array}{l}\text { A look at IoT protection problems and how blockchain can deal with the bulk of } \\
\text { them. }\end{array}$ \\
\hline Wang et al. [63] & A look at the effect of blockchain technology on IoT applications. \\
\hline Sengupta et al. [38] & $\begin{array}{l}\text { A look at the IIoT's security concerns. The authors have spoke about how } \\
\text { blockchain can help with these problems in the IIoT. }\end{array}$ \\
\hline Thakore et al. [64] & $\begin{array}{l}\text { A basic overview of the basics of IoT and blockchain, as well as how to combine the } \\
\text { two to achieve greater results. }\end{array}$ \\
\hline Patil et al. [52] & $\begin{array}{l}\text { To boost protection and privacy, a lightweight blockchain-based architecture for } \\
\text { smart greenhouse farms was proposed. }\end{array}$ \\
\hline Dogo et al. [53] & $\begin{array}{l}\text { To boost stability, accountability, and productivity in agriculture, a system for using } \\
\text { blockchain was proposed. }\end{array}$ \\
\hline Kadam and John [46] & $\begin{array}{l}\text { To fix the power problem in IoT devices, a platform based on the Ethereum } \\
\text { blockchain was proposed. }\end{array}$ \\
\hline Dorri et al. [40] & $\begin{array}{l}\text { To have a secure and private IoT scheme, a blockchain-based lightweight } \\
\text { architecture for IoT was proposed. }\end{array}$ \\
\hline Maroufi et al. [67] & $\begin{array}{l}\text { Examined the advantages and drawbacks of the integration of IoT and blockchain } \\
\text { technology. }\end{array}$ \\
\hline Alamri et al. [68] & $\begin{array}{l}\text { Examined the benefits and drawbacks of the integration of IoT and blockchain } \\
\text { technologies. }\end{array}$ \\
\hline Dukkipati et al. [47] & $\begin{array}{l}\text { To fix IoT protection and privacy problems, a blockchain-based access management } \\
\text { model was proposed. }\end{array}$ \\
\hline Lao et al. [69] & $\begin{array}{l}\text { An analysis of the core elements needed to combine blockchain with IoT was } \\
\text { presented. }\end{array}$ \\
\hline Polyzos and Fotiou [41] & An analysis of blockchain's ability to address IoT security issues was given. \\
\hline Atlam and Wills [2] & $\begin{array}{l}\text { An analysis of the integration of distributed ledger technology and the Internet of } \\
\text { Things framework was discussed. They have looked at blockchain and its key }\end{array}$ \\
\hline
\end{tabular}




\begin{tabular}{|c|l|}
\hline & benefits and drawbacks in relation to the IoT scheme. \\
\hline Novo [48] & $\begin{array}{l}\text { For the IoT system, a blockchain-based distributed access management system was } \\
\text { proposed. }\end{array}$ \\
\hline Hang and Kim [59] & $\begin{array}{l}\text { Proposed a blockchain-based integrated IoT network to ensure the data privacy of } \\
\text { data obtained from sensors. }\end{array}$ \\
\hline Zhang et al. [57] & $\begin{array}{l}\text { To achieve a trusted and distributed access model for the IoT framework, a smart } \\
\text { contract-based access management model was suggested. }\end{array}$ \\
\hline
\end{tabular}

\section{Section 5:}

\subsection{Blockchain as an assistance for the IoT}

Blockchain, as an innovation, can offer a layer of support that makes it easier to integrate the IoT design as previously described in Figure 5. Blockchain innovation and its highlights can be implemented on any computer domain, not simply in cryptocurrency, to fund multiple business by killing centrists and lowering costs. Blockchain can be used for various IoT implementations while distributed computing can provide its users with different management resources such as Software as a Service (SaaS), Platform as a Service (PaaS), and Infrastructure as a Service (IaaS) [75]. This is known as Blockchain as a Service (BaaS). BaaS focuses on designing, handling, promoting, and exploiting numerous blockchain engineering highlights across distributed computers, such as masterpieces, unaltered design, sealed, and distributed archives. As a consequence, based on the distributed computer system, blockchain will have diverse management. These panels would be needed for fog centres (IoT devices) to benefit from the highest levels of blockchain advancement in IoT mode. For IoT devices, BaaS may be introduced as PaaS or, more likely, as SaaS. While it is costly to incorporate blockchain as a requirement because it necessitates considerable expensive equipment to build a network and implement distributed innovation, it is worth it. [76]. BaaS is currently promoted by platforms such as Amazon, Microsoft Azure, Oracle, IBM Blockchain. The BaaS design is shown in Fig 6.

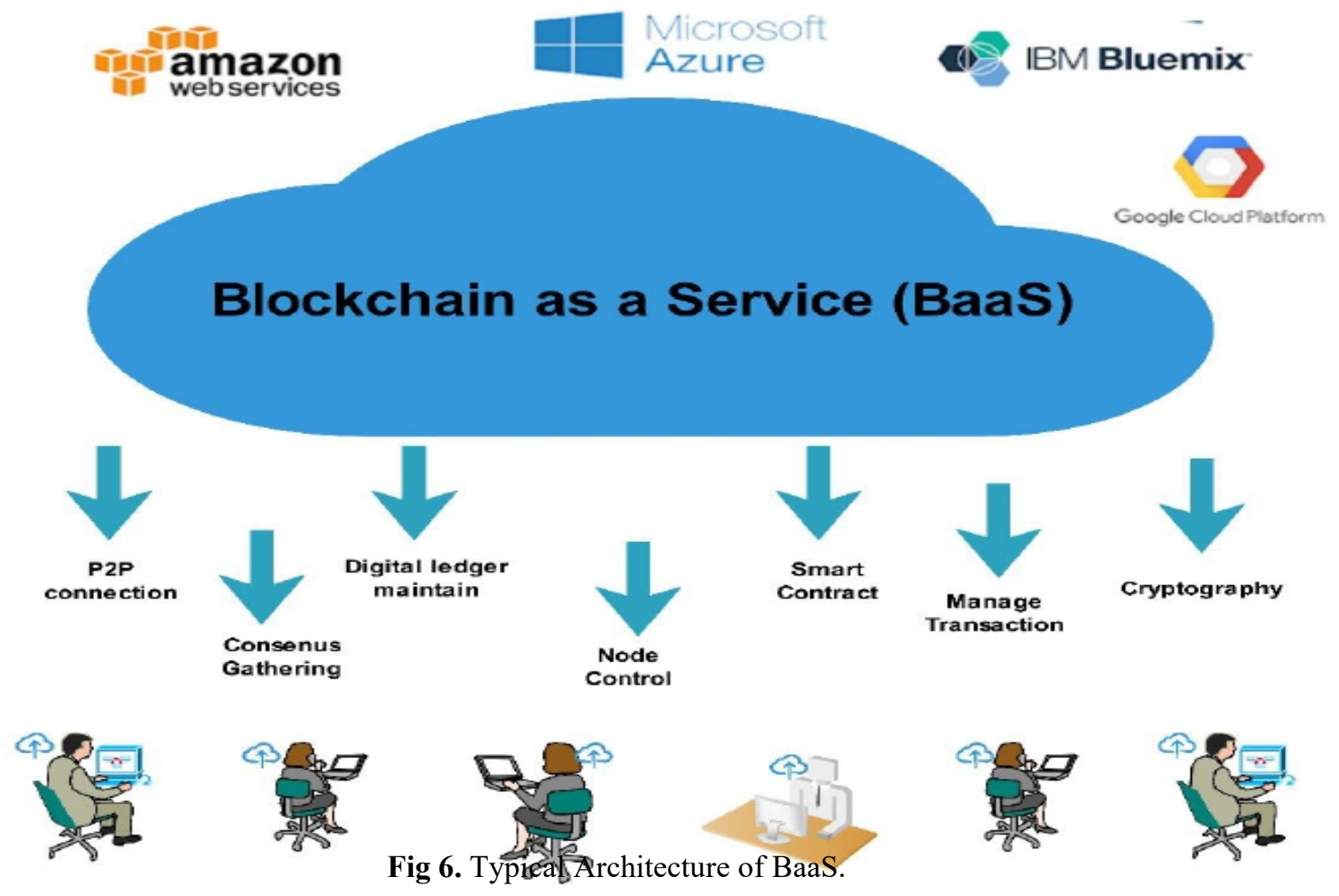

Section 6

6.1 Future scope of IoT with Blockchain 
Although integrating IoT with the blockchain has several advantages, it also raises many issues that should make plans to take full advantage of the two advances. This section provides an overview of future IoT research using blockchain innovation.

\section{Section 7 \\ 7.1 Conclusions}

With some of the difficulties introduced in the incorporated IoT design, it might be the right decision to incorporate IoT into one of the newly released innovations. Among the basic elements of a progression contribution is a blockchain. It uses a distributed methodology that conveys better productivity and releases a single level of disappointment. In addition, blockchain conveys better security and respect for information with sealed and durable highlights. Coordinating blockchain with IoT can solve issues in an IoT focused framework and provides an appropriate approach to future events. Thus, the aim of this article was to talk an exhaustive conversation about aligning the IoT framework with blockchain innovation. Following an overview of the IoT and blockchain premises, the paper went into detail on harmonizing the IoT blockchain by demonstrating how blockchain solved IoT problems. There are also several recent reports on the IoT blockchain. The blockchain as an IoT assist is then analysed in order to demonstrate how various aspects of blockchain engineering can be applied to various IoT implementations. This was generated by examining the effects of AI on IoT and blockchain. To that end, the potential quest instructions for IoT were discussed using blockchain.

\section{References}

1. Atlam, H.F.;Walters, R.J.;Wills, G.B. Internet of Things: State-of-the-art, Challenges, Applications, and Open Issues. Int. J. Intell. Comput. Res. 2018, 9, 928-938.

2. Atlam, H.F.; Alenezi, A.; Alassafi, M.O.; Wills, G.B. Blockchain with Internet of Things: Benefits, Challenges, and Future Directions. Int. J. Intell. Syst. Appl. 2018, 10, 40-48.

3. Fernandez-Carames, T.M.; Fraga-Lamas, P. A Review on the Use of Blockchain for the Internet of Things. IEEE Access 2018, 6, 32979-33001.

4. Atlam, H.F.; Wills, G.B. Intersections between IoT and distributed ledger. In Advances in Organometallic Chemistry Volume 60; Elsevier BV: Amsterdam, the Netherlands, 2019; pp. 73-113.

5. Karafiloski, E.; Mishev, A. Blockchain solutions for big data challenges: A literature review. In Proceedings of the IEEE EUROCON 2017-17th International Conference on Smart Technologies, Ohrid, Macedonia, 6-8 July 2017; pp. 763-768.

6. Reyna, A.; Martín, C.; Chen, J.; Soler, E.; Díaz, M. On blockchain and its integration with IoT. Challenges and opportunities. Future Gener. Comput. Syst. 2018, 88, 173-190.

7. ITU. Overview of the Internet of Things. Available online: https://www.itu.int/ITUT/recommendations/rec.aspx?rec=y.2060 (accessed on 13 October 2020)

8. Atlam, H.F.; Wills, G.B. Technical aspects of blockchain and IoT. In Advances in Organometallic Chemistry Volume 60; Elsevier BV: Amsterdam, the Netherlands, 2019; pp. 1-39.

9. Yin, S.; Lu, Y.; Li, Y. Design and implementation of IoT centralized management model with linkage policy. In Proceedings of the Third International Conference on Cyberspace Technology (CCT 2015), Beijing, China, 17-18 October 2015; pp. 5-9.

10. Atlam, H.F.; Wills, G.B. IoT Security, Privacy, Safety and Ethics. In Intelligent Sensing, Instrumentation and Measurements; Springer Science and Business Media LLC: Berlin, Germany, 2019; pp. 123-149.

11. Atlam, H.F.; Walters, R.J.; Wills, G.B. Internet of Nano Things. In Proceedings of the 2nd International Conference on Cloud and Big Data Computing (ICCBDC 2018), Barcelona, Spain, 3-5 August 2018; pp. $71-77$

12. Atlam, H.F.; Walters, R.J.; Wills, G.B. Intelligence of Things: Opportunities \& Challenges. In Proceedings of the 2018 3rd Cloudification of the Internet of Things (CIoT), Paris, France, 2-4 July 2018; pp. 1-6.

13. Conoscenti, M.; Vetro, A.; De Martin, J.C. Peer to Peer for Privacy and Decentralization in the Internet of Things. In Proceedings of the 2017 IEEE/ACM 39th International Conference on Software Engineering Companion (ICSE-C), Buenos Aires, Argentina, 20-28 May 2017; pp. 288-290.

14. Atlam, H.F.; Walters, R.J.; Wills, G.B. Fog Computing and the Internet of Things: A Review. Big Data Cogn. Comput. 2018, 2, 10.

15. Atlam, H.F.;Wills, G.B. An efficient security risk estimation technique for Risk-based access control model for IoT. Internet Things 2019, 6, 1-20.

16. Khan, M.A.; Salah, K. IoT security: Review, blockchain solutions, and open challenges. Future Gener. Comput. Syst. 2018, 82, 395-411. 
17. Coinbase. What Is the Bitcoin Blockchain? 2017. Available online: https://support.coinbase.com/customer/portal/articles/1819222-what-is-the-blockchain (accessed on 8 October 2020).

18. Sultan, K.; Ruhi, U.; Lakhani, R. Conceptualizing Blockchains: Characteristics \& Applications. arXiv 2018, arXiv: 1806.03693.

19. Biswas, K.; Muthukkumarasamy, V. Securing Smart Cities Using Blockchain Technology. In Proceedings of the 2016 IEEE 18th International Conference on High Performance Computing and Communications and IEEE 14th International Conference on Smart City and IEEE 2nd International Conference on Data Science and Systems (HPCC/SmartCity/DSS), Sydney, Australia, 12-14 December 2016; pp. 5-6.

20. Wu, H.; Li, Z.; King, B.; Ben Miled, Z.;Wassick, J.; Tazelaar, J. A Distributed Ledger for Supply Chain Physical Distribution Visibility. Information 2017, 8, 137.

21. Atlam, H.F.; Azad, M.A.; Alassafi, M.O.; Alshdadi, A.A.; Alenezi, A. Risk-Based Access Control Model: A Systematic Literature Review. Future Internet 2020, 12, 103.

22. Heilman, E.; Baldimtsi, F.; Goldberg, S. Blindly Signed Contracts: Anonymous On-Blockchain and Blockchain Bitcoin Transactions. In Proceedings of the Computer Vision; Springer Science and Business Media LLC: Berlin, Germany, 2016; Volume 9604, pp. 43-60.

23. Christidis, K.; Devetsikiotis, M. Blockchains and Smart Contracts for the Internet of Things. IEEE Access 2016, 4, 2292-2303.

24. Fabiano, N. Internet of Things and Blockchain: Legal Issues and Privacy. The Challenge for a Privacy Standard. In Proceedings of the 2017 IEEE International Conference on Internet of Things (iThings) and IEEE Green Computing and Communications (GreenCom) and IEEE Cyber, Physical and Social Computing (CPSCom) and IEEE Smart Data (SmartData), Exeter, UK, 21-23 June 2017; pp. 727-734.

25. Ferraro, P.; King, C.; Shorten, R. Distributed Ledger Technology for Smart Cities, the Sharing Economy, and Social Compliance. IEEE Access 2018, 6, 62728-62746.

26. Alkurdi, F.; Elgendi, I.; Munasinghe, K.S.; Sharma, D.; Jamalipour, A. Blockchain in IoT Security: A Survey. In Proceedings of the 28th International Telecommunication Networks and Applications Conference (ITNAC), Sydney, Australia, 21-23 November 2018; pp. 1-4.

27. Hang, L.; Kim, D.-H. Design and Implementation of an Integrated IoT Blockchain Platform for Sensing Data Integrity. Sensors 2019, 19, 2228.

28. Panarello, A.; Tapas, N.; Merlino, G.; Longo, F.; Puliafito, A. Blockchain and IoT Integration: A Systematic Survey. Sensors 2018, 18, 2575.

29. Wood, G. Ethereum: A secure decentralised generalised transaction ledger. Ethereum Proj. Yellow Pap. 2014, 151, 1-32.

30. Sun, H.; Hua, S.; Zhou, E.; Pi, B.; Sun, J.; Yamashita, K. Using Ethereum Blockchain in Internet of Things: A Solution for Electric Vehicle Battery Refueling. In Lecture Notes in Computer Science (Including Subseries Lecture Notes in Artificial Intelligence and Lecture Notes in Bioinformatics); Springer: Berlin/Heidelberg, Germany, 2018; Volume 10974, pp. 3-17.

31. Mehedi, S.K.T.; Shamim, A.A.M.; Miah, M.B.A. Blockchain-based security management of IoT infrastructure with Ethereum transactions. Iran J. Comput. Sci. 2019, 2, 189-195.

32. Samaniego, M.; Deters, R. Hosting Virtual IoT Resources on Edge-Hosts with Blockchain. In Proceedings of the 2016 IEEE International Conference on Computer and Information Technology (CIT), Nadi, Fiji, 810 December 2016; pp. 116-119.

33. Franke, L.A.; Schletz, M.; Salomo, S. Designing a Blockchain Model for the Paris Agreement's Carbon Market Mechanism. Sustainability 2020, 12, 1068.

34. Pongnumkul, S.; Siripanpornchana, C.; Thajchayapong, S. Performance Analysis of Private Blockchain Platforms in Varying Workloads. In Proceedings of the 2017 26th International Conference on Computer Communication and Networks (ICCCN), Vancouver, BC, Canada, 31 July-3 August 2017; pp. 1-6.

35. Raschendorfer, A.; Mörzinger, B.; Steinberger, E.; Pelzmann, P.; Oswald, R.; Stadler, M.; Bleicher, F. On IOTA as a potential enabler for an M2M economy in manufacturing. Procedia CIRP 2019, 79, 379-384.

36. Shabandri, B.; Maheshwari, P. Enhancing IoT Security and Privacy Using Distributed Ledgers with IOTA and the Tangle. In Proceedings of the 2019 6th International Conference on Signal Processing and Integrated Networks (SPIN), Noida, India, 7-8 March 2019; pp. 1069-1075.

37. Elsts, A.; Mitskas, E.; Oikonomou, G. Distributed Ledger Technology and the Internet of Things. In Proceedings of the 1st Workshop on Blockchain-enabled Networked Sensor Systems-BlockSys'18 Shenzhen, China, 4 November 2018; pp. 7-12. 
38. Sengupta, J.; Ruj, S.; Das Bit, S. A Comprehensive Survey on Attacks, Security Issues and Blockchain Solutions for IoT and IIoT. J. Netw. Comput. Appl. 2020, 149, 102481.

39. Banerjee, M.; Lee, J.; Choo, K.-K.R. A blockchain future for internet of things security: A position paper. Digit. Commun. Netw. 2018, 4, 149-160.

40. Dorri, A.; Kanhere, S.S.; Jurdak, R. Blockchain in internet of things: Challenges and Solutions. 2016, 1608.05187.

41. Polyzos, G.C.; Fotiou, N. Blockchain-Assisted Information Distribution for the Internet of Things. In Proceedings of the 2017 IEEE International Conference on Information Reuse and Integration (IRI), San Diego, CA, USA, 4-6 August 2017; pp. 75-78.

42. Karthikeyyan, P.; Velliangiri, S.; S, I.T.J. Review of Blockchain based IoT application and its security issues. In Proceedings of the 2019 2nd International Conference on Intelligent Computing, Instrumentation and Control Technologies (ICICICT), Kannur, India, 5-6 July 2019; pp. 6-11.

43. Fotiou, N.; Siris, V.A.; Polyzos, G.C. Interacting with the Internet of Things Using Smart Contracts and Blockchain Technologies. In Lecture Notes in Computer Science (Including Subseries Lecture Notes in Artificial Intelligence and Lecture Notes in Bioinformatics); Springer: Berlin/Heidelberg, Germany, 2018; Volume 11342, 55 pp. 443-452.

44. Tandon, A. An empirical analysis of using blockchain technology with internet of things and its application. Int. J. Innov. Technol. Explor. Eng. 2019, 8, 1470-1475.

45. Zhu, X.; Badr, Y. Identity Management Systems for the Internet of Things: A Survey towards Blockchain Solutions. Sensors 2018, 18, 4215.

46. Kadam, S.B.; John, S.K. Blockchain Integration with Low-Power Internet of Things Devices; Elsevier BV: Amsterdam, the Netherlands, 2020; pp. 183-211.

47. Dukkipati, C.; Zhang, Y.; Cheng, L.C. Decentralized, BlockChain Based Access Control Framework for the Heterogeneous Internet of Things. In Proceedings of the Third ACMWorkshop on Attribute-Based Access Control-ABAC'18, Tempe, AZ, USA, 19-21 March 2018; pp. 61-69.

48. Novo, O. Blockchain Meets IoT: An Architecture for Scalable Access Management in IoT. IEEE Int. Things J. 2018, 5, 1184-1195.

49. Zhang, Y.; Kasahara, S.; Shen, Y.; Jiang, X.;Wan, J. Smart Contract-Based Access Control for the Internet of Things. IEEE Int. Things J. 2018, 6, 1594-1605.

50. Badr, S.; Gomaa, I.; Abd-Elrahman, E. Multi-tier Blockchain Framework for IoT-EHRs Systems. Procedia Comput. Sci. 2018, 141, 159-166.

51. Mishra, S.; Tyagi, A.K. Intrusion Detection in Internet of Things (IoTs) Based Applications using Blockchain Technolgy. In Proceedings of the 2019 Third International Conference on I-SMAC (IoT in Social, Mobile, Analytics and Cloud) (I-SMAC), Palladam, India, 12-14 December 2019; pp. 123-128.

52. Patil, A.S.; Tama, B.A.; Park, Y.; Rhee, K.H. A Framework for Blockchain Based Secure Smart Green House Farming. In Lecture Notes in Electrical Engineering; Springer Science and Business Media LLC: Berlin, Germany, 2017; Volume 474, pp. 1162-1167.

53. Dogo, E.M.; Salami, A.F.; Nwulu, N.I.; Aigbavboa, C.O. Blockchain and Internet of Things-Based Technologies 64. For Intelligent Water Management System; Springer Science and Business Media LLC: Berlin, Germany, 2019; 65. pp. 129-150.

54. Kamilaris, A.; Fonts, A.; Prenafeta-Bold , F.X. The rise of blockchain technology in agriculture and food supply chains. Trends Food Sci. Technol. 2019, 91, 640-652.

55. Rejeb, A.; Keogh, J.G.; Treiblmaier, H. Leveraging the Internet of Things and Blockchain Technology in Supply Chain Management. Future Int. 2019, 11, 161.

56. Huckle, S.; Bhattacharya, R.; White, M.; Belo_, N. Internet of Things, Blockchain and Shared Economy Applications. Procedia Comput. Sci. 2016, 98, 461-466.

57. Zhang, Y.;Wen, J. The IoT electric business model: Using blockchain technology for the internet of things. Peer-To-Peer Netw. Appl. 2016, 10, 983-994.

58. Ruta, M.; Scioscia, F.; Ieva, S.; Capurso, G.; Di Sciascio, E. Regular research paper: Blockchain, ServiceOriented Architecture, Semantic Web of Things, Semantic Web. J. Int.Things 2017, 3, 46-61.

59. Huh, S.; Cho, S.; Kim, S. Managing IoT devices using blockchain platform. In Proceedings of the 2017 19th International Conference on Advanced Communication Technology (ICACT), Bongpyeong, Korea, 19-22 February 2017; pp. 464-467.

60. Conoscenti, M.; Vetro, A.; De Martin, J.C. Blockchain for the Internet of Things: A systematic literature review. In Proceedings of the 2016 IEEE/ACS 13th International Conference of Computer Systems and Applications (AICCSA), Agadir, Morocco, 29 November-2 December 2016; pp. 1-6. 
61. Lo, S.K.; Liu, Y.; Chia, S.Y.; Xu, X.; Lu, Q.; Zhu, L.; Ning, H. Analysis of Blockchain Solutions for IoT: A Systematic Literature Review. IEEE Access 2019, 7, 58822-58835

62. Abadi, F.A.; Ellul, J.; Azzopardi, G. The Blockchain of Things, Beyond Bitcoin: A Systematic Review. In Proceedings of the 2018 IEEE International Conference on Internet of Things (iThings) and IEEE Green Computing and Communications (GreenCom) and IEEE Cyber, Physical and Social Computing (CPSCom) and IEEE Smart Data (SmartData), Halifax, NS, Canada, 30 July-3 August 2018; pp. 1666-1672.

63. Wang, X.; Zha, X.; Ni, W.; Liu, R.P.; Guo, Y.J.; Niu, X.; Zheng, K. Survey on blockchain for Internet of Things. Comput. Commun. 2019, 136, 10-29.

64. Thakore, R.; Vaghashiya, R.; Patel, C.; Doshi, N. Blockchain-Based IoT: A Survey. Procedia Comput. Sci. 2019, 155, 704-709.

65. Ferrag, M.A.; Maglaras, L.; Janicke, H. Blockchain and Its Role in the Internet of Things. In Strategic Innovative Marketing and Tourism; Springer Proceedings in Business and Economics, Kavoura, A., Kefallonitis, E., Giovanis, A., Eds.; Springer: Cham, Switzerland, 2019; pp. 151-157.

66. Dai, H.-N.; Zheng, Z.; Zhang, Y. Blockchain for Internet of Things: A Survey. IEEE Int. Things J. 2019, 6, 8076-8094.

67. Maroufi, M.; Abdolee, R.; Tazekand, B.M. On the Convergence of Blockchain and Internet of Things (IoT) Technologies. J. Strat. Innov. Sustain. 2019, 14, 1-11.

68. Alamri, M.; Jhanjhi, N.Z.; Humayun, M. Blockchain for Internet of Things (IoT) Research Issues Challenges \& Future Directions: A Review. Int. J. Comput. Sci. Netw. Secur. 2019, 19, 244-258.

69. Lao, L.; Li, Z.; Hou, S.; Xiao, B.; Guo, S.; Yang, Y. A Survey of IoT Applications in Blockchain Systems. ACM Comput. Surv. 2020, 53, 1-32.

70. Singh, J.; Michels, J.D. Blockchain as a Service (BaaS): Providers and Trust. In Proceedings of the 2018 IEEE European Symposium on Security and Privacy Workshops (EuroS\&PW), London, UK, 23-27 April 2018; pp. 67-74.

71. Artificial Intelligence|Definition of Artificial Intelligence by Merriam-Webster. Available online: https://www.merriam-webster.com/dictionary/artificialintelligence (accessed on 24 April 2020).

72. Reddy, R. The challenge of artificial intelligence. Comput. Long. Beach. Calif 1996, 29, 86-98.

73. Alzahrani, A.G.; Alenezi, A.; Atlam, H.; Wills, G.B. A Framework for Data Sharing between Healthcare Providers using Blockchain. In Proceedings of the 5th International Conference on Internet of Things, Big Data and Security (IoTBDS 2020), Prague, Czech Republic, 7-9 May 2020; pp. 349-358.

74. Baldominos, A.; Saez, Y. Coin.AI: A Proof-of-Useful-Work Scheme for Blockchain-Based Distributed Deep Learning. Entropy 2019, 21, 723.

75. Bilodeau, S. Massive Computing for Bitcoin Mining and AI. Available online: https://towardsdatascience. Com/energy-smart-bitcoin-mining-dd7bd2d2a3fa (accessed on 8 October 2020).

76. Roman, R.; Zhou, J.; Lopez, J. On the features and challenges of security and privacy in distributed internet of things. Comput. Netw. 2013, 57, 2266-2279 